\title{
Upper thermospheric neutral wind and temperature measurements from an extended spatial field
}

\author{
E. M. Griffin ${ }^{1}$, A. L. Aruliah ${ }^{1}$, I. McWhirter ${ }^{1}$, H.-C. I. Yiu ${ }^{1}$, A. Charalambous ${ }^{1}$, and I. McCrea ${ }^{2}$ \\ ${ }^{1}$ Atmospheric Physics Laboratory, University College London, Gower Street, London WC1E 6BT, UK \\ ${ }^{2}$ EISCAT Support Group, Rutherford Appleton Laboratory, Chilton, Didcot, OX11 0QX, UK
}

Received: 8 May 2008 - Revised: 4 August 2008 - Accepted: 11 August 2008 - Published: 12 September 2008

\begin{abstract}
First results are presented from a Scanning Doppler Imager (SCANDI) installed at the Nordlysstasjonen optical observatory near Longyearbyen, Svalbard $\left(78.2^{\circ} \mathrm{N}\right.$, $15.8^{\circ} \mathrm{E}$ ). Observations of the atomic oxygen $630 \mathrm{~nm}$ red line emission, originating in the upper thermosphere at around $250 \mathrm{~km}$, have been used to determine neutral winds and temperatures from multiple zones within an extended spatial field. The instrument utilises all-sky optics to achieve multiple simultaneous measurements, compared to the standard Fabry-Perot Interferometer (FPI) procedure of separate lineof-sight samples within a sequence of narrow angle look directions. SCANDI is colocated with such a standard FPI and comparison of neutral wind velocities between the instruments on the night of 15 March 2007 has revealed detailed and consistent structure in the wind field. Southward meridional wind enhancements of several hundred $\mathrm{m} / \mathrm{s}$ are observed simultaneously with both instruments, revealing structure on scales not currently considered in thermospheric general circulation models (GCMs). The data from this night also demonstrate the influence of discrete auroral events on thermospheric behaviour. High intensities observed by SCANDI in the presence of auroral arcs coincide with a drop in measured neutral temperatures. This is interpreted as a result of the effective altitude of the $630 \mathrm{~nm}$ emission being lowered under conditions of soft auroral precipitation. The optical instruments as a consequence sample a region of lower temperature. This effect has been observed previously with lower thermospheric atomic oxygen emissions at $557.7 \mathrm{~nm}$. The EISCAT Svalbard Radar (ESR) provides ion temperatures and electron densities for the night which confirm the influence of precipitation and heating during the auroral events. The minima of ion temperatures through the pre-midnight period provide a good match to the neutral tem-
\end{abstract}

Correspondence to: E. M. Griffin

(eoghan@apl.ucl.ac.uk) peratures measured with SCANDI, and to the colocated FPI temperatures.

Keywords. Atmospheric composition and structure (Airglow and aurora; Instruments and techniques) - Ionosphere (Ionosphere-atmosphere interactions)

\section{Introduction}

Fabry-Perot Interferometers have been used for many years to measure upper thermospheric winds and temperatures by observing the atomic oxygen $630 \mathrm{~nm}$ red line emission and fitting calculated spectra to the recorded profiles (e.g. Burnside et al., 1981; Killeen et al., 1995). These measurements are usually recorded as a sequence of observations taken using a fixed elevation angle around the cardinal directions in either geographic or geomagnetic coordinates, together with calibration and zenith measurements. Assumptions about the uniformity of the thermospheric winds and temperatures are often made in comparing the measurements from these sequences. At high latitudes it has become clear in recent years that significant structure is apparent within the FPI field of view which is of the order of several hundred $\mathrm{km}$ (Greet et al., 1999; Aruliah and Griffin, 2001; Aruliah et al., 2004). A number of instruments have been developed to produce multiple simultaneous estimates of winds and temperatures from an extended all-sky field of view (e.g. Rees et al., 1984; Biondi et al., 1995; Nakajima et al., 1995). The instruments imaged multiple Fabry-Perot rings from fixed gap etalons to provide a range of concentric samples across the field of view. In more recent times Conde and Smith (1997) have demonstrated a concept using a scanning etalon which realises the idea in a practical and flexible way by implementing phase compensation for each detector element or pixel. This instrument has been used in combination with

Published by Copernicus Publications on behalf of the European Geosciences Union. 
a conventional FPI to investigate high latitude thermospheric vertical winds (Ishii et al., 2001). The SCANDI instrument utilises the same concept and uses the latest CCD technology to deliver the combination of stability and sensitivity required by the detection system. The Atmospheric Physics Laboratory (APL) at University College London operates an existing standard FPI at Longyearbyen and the combination of the ability to cross-calibrate with this FPI and the unique abundance of colocated complementary instrumentation, including the ESR incoherent scatter radar and Cutlass SuperDARN radars, led to the SCANDI instrument being installed at Longyearbyen, Svalbard.

\section{SCANDI instrument}

SCANDI uses an all-sky fore-optics system. This includes a fish-eye lens of which the central $150^{\circ}$ of the field of view are used. This is then beam expanded to fill the aperture of a piezo-electrically scanned, $150 \mathrm{~mm}$ aperture, Fabry-Perot etalon. A filter wheel and calibration system are also included in the fore-optics. This allows for the option of observing $630 \mathrm{~nm}, 557.7 \mathrm{~nm}$ and $732 \mathrm{~nm}$ emissions corresponding to neutral upper thermosphere, neutral lower thermosphere and ionospheric measurements, respectively. All initial results presented here were obtained from the $630 \mathrm{~nm}$ emission. A calibration panel is sampled by the etalon by means of a two-position mirror. This panel may be illuminated via fibre-optic connector by either a calibration lamp $(630.6 \mathrm{~nm})$, used to assess instrumental drift, or a frequency stabilised He-Ne laser $(632.8 \mathrm{~nm})$, which provides calibration for Doppler width and hence allows temperature determination.

The detector used is an Andor iXon 887 which utilises a $512 \times 512 \mathrm{e} 2 \mathrm{v}$ Electron Multiplying CCD (EMCCD) chip. This detector has been found to be suitably sensitive for pseudo-photon counting operation, needed in the scanning Doppler imager implementation, while retaining the excellent linearity characteristics typical of modern scientific CCDs.

Several concentric interference rings are imaged onto the chip and then progressively scanned through one full order of wavelength which allows each CCD pixel to act in principle as the equivalent of a separate detector. By application of a phase map (see Conde and Smith, 1997) the response of each pixel throughout a complete scan can be shifted to correspond to the same wavelength range. In practice the CCD is split into many zones, with the pixels in each zone combined to provide sufficient signal to noise ratio to allow accurate determination of winds and temperatures from the standard line fitting techniques. Each integration is made up of several scans and for the measurements presented here the average time between observations was $\sim 7 \min (439 \mathrm{~s})$. The zero baselines for the derived winds were determined by averaging the LOS shifts for all zones within each ring over the course of a full night. The averages thus produced were tested for stability on a night to night basis and found to be reliable.

\subsection{Fabry-Perot interferometer}

The FPI at Longyearbyen is similar to the APL instruments described in Aruliah et al. (2005). It has a Fabry-Perot etalon with $150 \mathrm{~mm}$ diameter and makes observations of the $630 \mathrm{~nm}$ emission with a $1^{\circ}$ field-of-view using a scanning mirror sampling at a $30^{\circ}$ elevation angle. A neon calibration lamp and $\mathrm{He}-\mathrm{Ne}$ laser are used for calibration of wind and temperature measurements. A sequence of cardinal directions, zenith and calibration measurements are taken consecutively. The instrument currently uses an Andor iXon 887 detector, identical to that used on the SCANDI instrument. The integration time used for the winter 2006/07 season was $30 \mathrm{~s}$ producing an average sequence cycle time of $\sim 6 \min (362 \mathrm{~s})$. The LOS shifts from the vertical direction are averaged over the full night and used as the baseline for the wind calculations. Instrumental drift is monitored using calibration images from each observation sequence.

\section{Results}

The instrument was installed at Longyearbyen in December 2006 and initial tests were performed using a static multiring imaging arrangement similar to that used by Rees and Greenaway (1983) and Nakajima et al. (1995). In late February 2007 a scanning mode was implemented which allowed the entire field of view to be sampled. Initial tests were undertaken with a 25 zone configuration as shown in Fig. 1, and this configuration was in operation on the night of 15 March 2007. The arrangement provides 6 zones in each cardinal direction relative to the central zone. Operating in parallel with SCANDI was the co-located FPI. Each of the cardinal look directions of the FPI, sampled at $30^{\circ}$ elevation and with a $1^{\circ}$ field of view, overlap with one of the SCANDI zones. North from the FPI is contained within SCANDI zone 15 as shown in Fig. 1, South within zone 21, East within zone 24 and West within zone 18. These outer SCANDI zones each contain a range of elevations from $23^{\circ}$ to $40^{\circ}$ and extend through $30^{\circ}$ of azimuth. The approximate scales when projected to the atomic oxygen emission altitude of $250 \mathrm{~km}$ are $220 \mathrm{~km}$ between the centers of each outer zone.

\subsection{Thermospheric winds and temperatures - 15 March 2007}

Figure 2 shows the comparison of FPI North and SCANDI zone 15 line-of-sight (LOS) winds from 18:00 UT on 15 March to 04:00 UT on 16 March. The figure shows considerable structure throughout the night with predominantly southward winds up to 22:00 UT followed by a brief excursion to slightly northward winds. After 22:30 UT the 


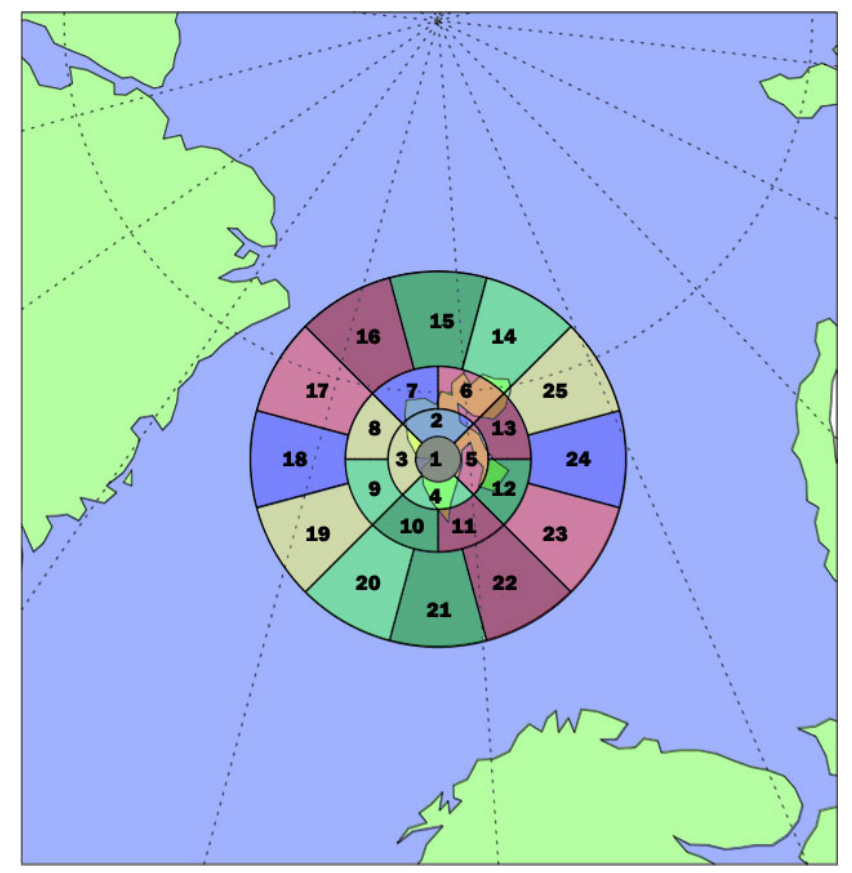

Fig. 1. SCANDI zone map showing the field-of-view of each zone. The full field-of-view has a radius of $590 \mathrm{~km}$ for $630 \mathrm{~nm}$ emission peak altitude of $250 \mathrm{~km}$.

winds turn southward and remain so until 04:00 UT. Both the general trend and most of the detailed structure are closely matched in the SCANDI and FPI LOS winds, although the FPI winds in general have the highest velocities whenever a difference is apparent. Of note are the period between 21:00 UT and 22:15 UT, where the winds appear to oscillate from northward to southward, and the following period between 22:15 UT and 00:15 UT where a strong southward surge is recorded by both instruments. The change in neutral wind LOS velocity in the hour after 22:15 UT is dramatic, appearing to be over $300 \mathrm{~m} / \mathrm{s}$ as measured by the FPI and at least $250 \mathrm{~m} / \mathrm{s}$ as measured by SCANDI. There is considerable structure to this surge with two distinct peaks in velocity at around 23:15 UT and 23:45 UT which are again recorded in both instruments. The fall in neutral velocities from their premidnight peak to the post midnight level around 00:30 UT is almost as dramatic as the initial rise, again being of the order of several hundred $\mathrm{m} / \mathrm{s}$ within an hour as measured by both instruments. The FPI velocities are up to $50 \mathrm{~m} / \mathrm{s}$ higher than the SCANDI velocities for both peaks throughout this period of enhanced southward winds. This may be attributed to the geometry of the LOS samples as the SCANDI LOS consists of contributions from a range of elevations, (Fig. 1), while the FPI will sample from a fixed $30^{\circ}$ elevation. Assuming symmetry the zonal component over the $30^{\circ}$ azimuth covered by SCANDI zone 15 will cancel out.

Figure 3 is a panel plot comparison of the thermospheric measurements from SCANDI with ionospheric measure-

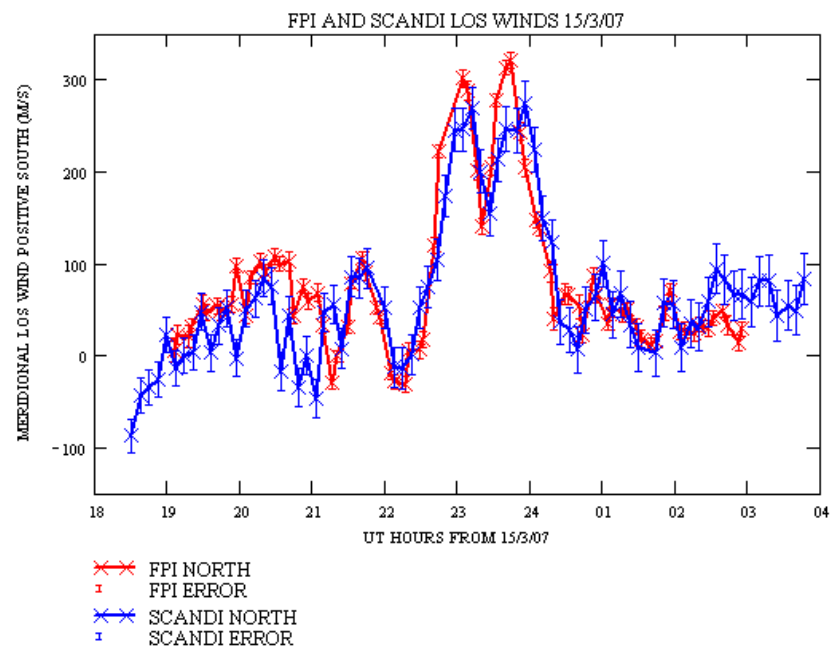

Fig. 2. A close correspondence shown between SCANDI (zone 15) and FPI LOS Winds looking north from the night of 15 March 2007. FPI LOS winds are systematically larger owing to a much smaller field-of-view. Winds are positive southward.

ments from the ESR. The top panel (a) shows electron densities, (b) shows ion temperatures, (c) shows neutral winds, (d) shows neutral temperatures and (e) shows relative intensities of the $630 \mathrm{~nm}$ emission in arbitrary units.

The ESR plots show altitude versus time. The data are from the $42 \mathrm{~m}$ dish radar which was in a fixed field-aligned position undertaking a long term International Polar Year (IPY) experiment. There are 3 periods of importance. The first two are periods of particle precipitation which enhance the electron density. However, they differ in their consequences owing to where the energy is deposited in the upper atmosphere. Between 21:15 UT and 21:30 UT there is an Fregion (200-300 km altitude) enhancement by a factor of 3 with a small enhancement in the E-region $(100-200 \mathrm{~km}$ altitude). The second period is between 21:45-22:10 UT, and shows electron density enhancement peaking in the E-region, with a smaller enhancement of the F-region. The ion temperatures corresponding to these periods show little effect from the first period of precipitation but a large increase from the second. The third period of interest is between 22:3000:20 UT which shows low electron densities, yet several periods of enhanced ion temperature.

Figure $3 \mathrm{c}$ compares the SCANDI LOS winds. The measurements indicate the zonal structure over a distance of around $660 \mathrm{~km}$ by comparing SCANDI zone 15 (blue=North) with each zone on either side (red=NNE=zone 14; green=NNW=zone 16). From this plot we can see that the general trends are consistent for each of the zones, but there is clear and significant zonal structure over this short distance. This challenges the earlier assumption of zonal symmetry when interpreting the SCANDI zone 15 winds. The surge in southward winds 


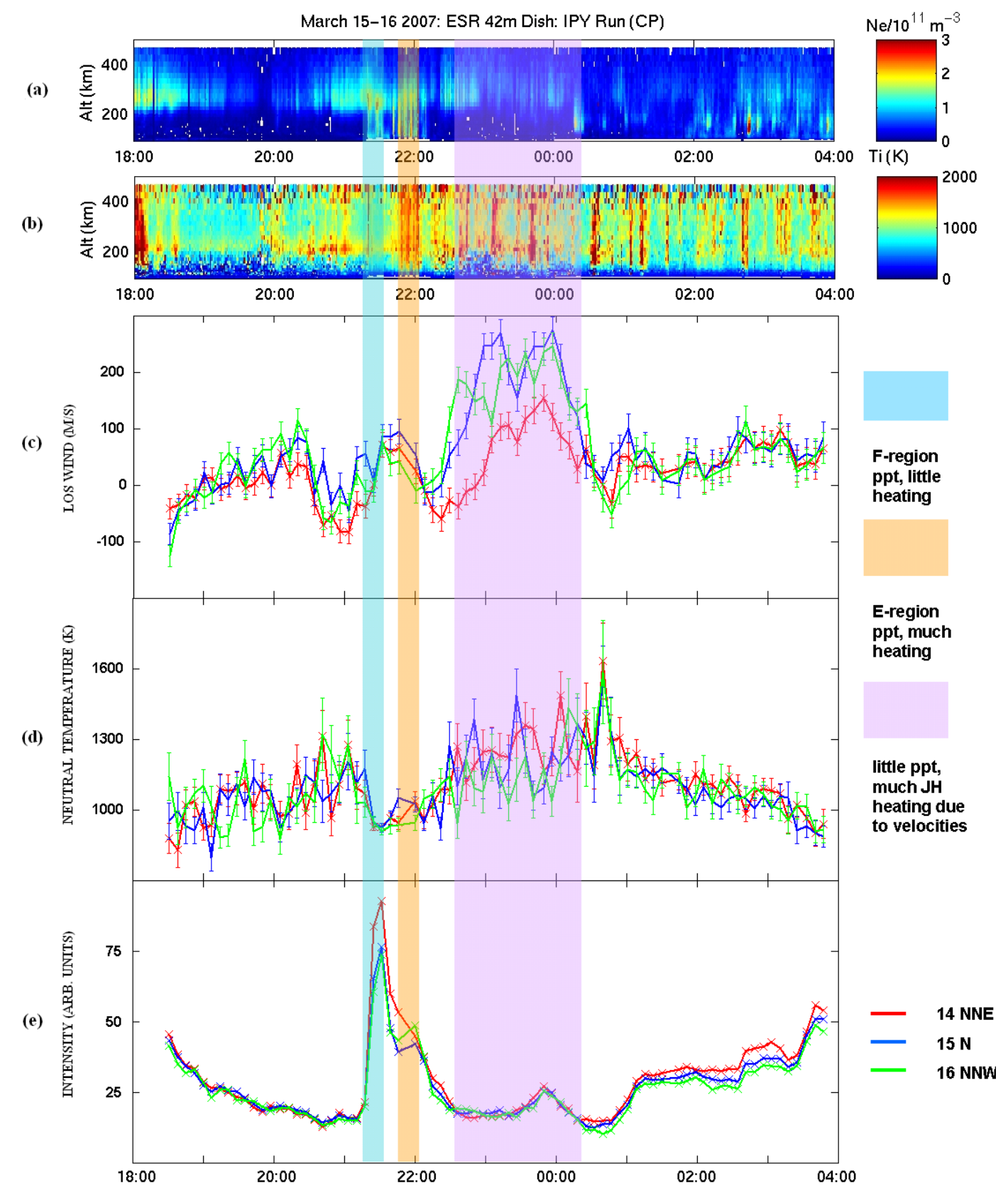

Fig. 3. ESR Ion temperatures and electron densities (panels a and b, respectively) compared with SCANDI LOS winds, neutral temperatures and intensities (panels c, $\mathbf{d}$ and e, respectively) for zones 14 (red), 15 (blue) and 16 (green) as shown in Fig. 1.

observed between 22:15 UT and 00:15 UT is also seen in the adjacent zones. The comparison however shows significant differences in the LOS winds from this period, in particular the largest speeds are recorded in the North and smallest in NNE. This is due to a mixture of meso-scale spatial structure and the integration of LOS winds over a sky sector with azimuth $30^{\circ}$ for the SCANDI outer zones. A distance of around $220 \mathrm{~km}$ separates the centre of zone 15 from adjacent zones 14 and 16 centres. Generally thermospheric flow over the polar cap is antisunward, and so over the nighttime sector it will have a large southward meridional component and smaller zonal component. The North sector LOS measurements are purely meridional, while the smaller LOS winds from the NNE and NNW sectors come from the geometry of a large meridional component with a contribution from a small zonal component. At times there can be as much as a $200 \mathrm{~m} / \mathrm{s}$ difference between the sectors due to the fluctuation in the direction of the wind vector. When the North LOS wind is largest, i.e. dominant meridional wind component, the asymmetry between the NNE and 


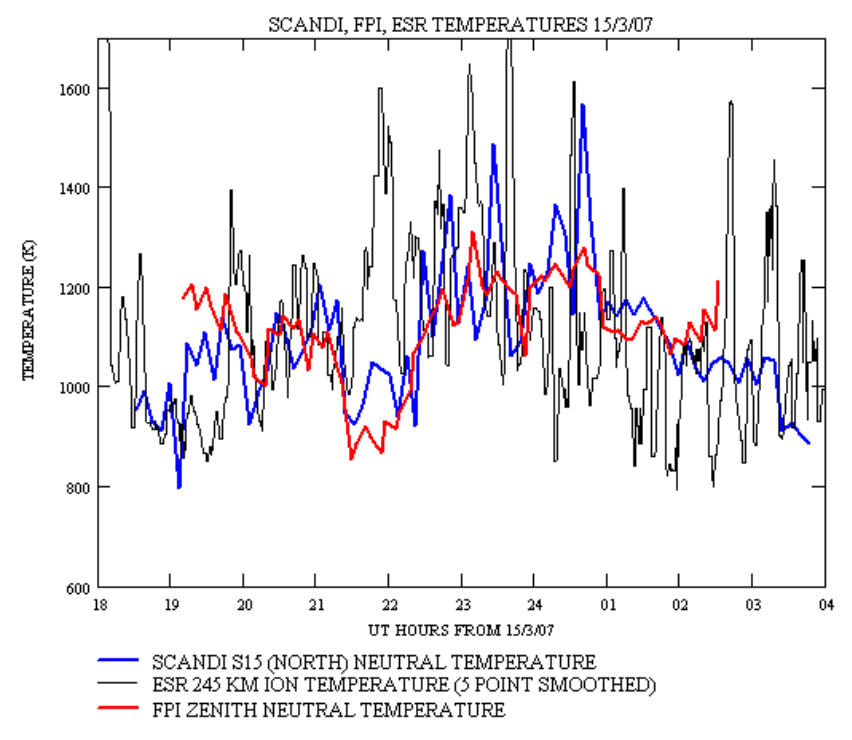

Fig. 4. SCANDI zone 15 (North) neutral temperatures compared with FPI zenith neutral temperatures and ESR ion temperatures (5 point smoothed) from $245 \mathrm{~km}$ altitude for 15 March 2007.

NNW LOS winds could be interpreted as a zonal gradient in the wind vector with respect to distance across the zones. From Fig. 2 it can be seen that significant differences also exist between the SCANDI and FPI winds from 19:00 UT to 21:00 UT, although Fig. 3 indicates there are no dramatic changes in the state of the thermosphere or ionosphere at this time. Figure $3 \mathrm{c}$ does however show differences in the winds between the SCANDI zones and this suggests the differences between SCANDI and FPI winds results from the different sampling of this spatial wind structure due to their differing viewing geometries. The influence of localized structure on the wind results from adjacent zones will be discussed in more detail in a following paper.

Figure $3 \mathrm{~d}$ shows that the neutral temperatures are consistent within around $100 \mathrm{~K}$ between the 3 zones. Of particular note is the period from 21:30 UT to 22:15 UT which shows a sharp drop in the temperature from around $1100 \mathrm{~K}$ to $900 \mathrm{~K}$ for all 3 zones followed by a gradual recovery to the pre21:30 UT levels. Following this, there is a gradual temperature increase to a peak around 00:30 UT at about $1400 \mathrm{~K}$ which is then followed by a gradual fall to around $900 \mathrm{~K}$. During this latter period (01:00-04:00 UT) the temperatures are identical within the errors.

Figure $3 \mathrm{e}$ shows the relative intensity of the $630 \mathrm{~nm}$ emission. There is a sharp increase in intensity at 21:20 UT lasting around $10 \mathrm{~min}$ and then decaying over the next hour. This is observed in all 3 zones and corresponds to the temperature drop seen in Fig. 3d. Other than this short period, the emission intensity is virtually identical for all 3 zones.

Figure 4 shows the meridional structure over the SCANDI field-of-view (a horizontal distance of around $600 \mathrm{~km}$ ) of the neutral temperature at an altitude around $250 \mathrm{~km}$ by com-

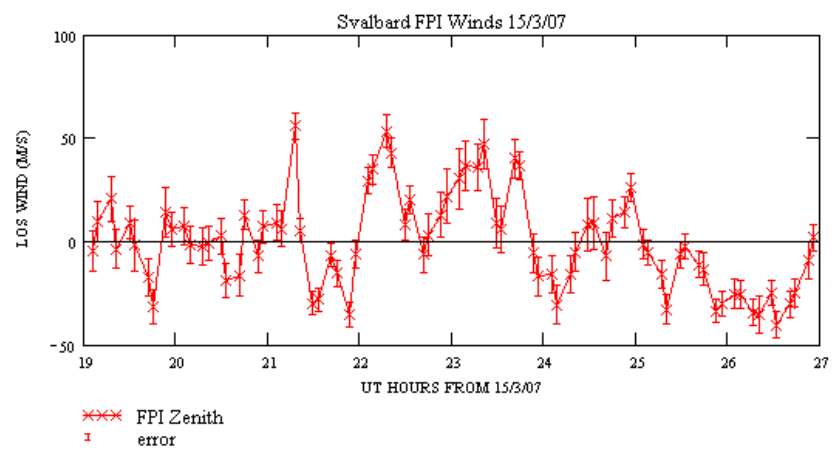

Fig. 5. FPI zenith wind measurements for 15 March 2007. Positive winds indicate upwelling.

paring the SCANDI sector 15 (North) with the FPI zenith. These instruments have been independently calibrated and show good agreement throughout the night including the pe$\operatorname{riod} 21: 20 \mathrm{UT}$ to 22:00 UT when both instruments record a sharp drop in temperature of over $200 \mathrm{~K}$ followed by a gradual rise after 22:00 UT.

Also shown are the ESR ion temperatures from $245 \mathrm{~km}$, which is the range gate closest to the nominal peak $630 \mathrm{~nm}$ emission altitude, and are point measurements from the fieldaligned direction. The closest neutral temperatures for comparison are those from the FPI zenith. The ion temperatures are highly variable, probably due to the relatively low electron densities through the night, and so have been 5-point smoothed. In the pre-midnight period the ion temperatures appear to approximate the neutral temperature reasonably well. However, in the period 21:30-22:15 UT the ion temperatures rise significantly at the same time as the dramatic drop in neutral temperature. In the post-midnight period the ion temperatures appear to be lower than neutral temperature in general, which seems anomalous. This could be due to poor signal from the low electron densities at this time, or possibly the result of ion composition changes.

Figure 5 shows the neutral velocities from the zenith observations of the FPI throughout the night of 15 March 2007. Of particular interest is the period from 22:00 to just before 24:00 UT where consistent and large positive (upward) velocities are recorded indicating sustained upwelling. This upwelling may be expected to produce an altered ratio of atoms to molecules at $245 \mathrm{~km}$.

\section{Discussion}

The initial data from the SCANDI instrument has demonstrated both reliable estimates of upper thermospheric winds and temperatures and also evidence of the structure within the extended field of view provided by this type of instrument. The impact of mesoscale thermospheric structure has only recently been considered, and is becoming relevant to the development of the coupled thermospheric-ionospheric 
GCMs (e.g. Codrescu et al., 2000; Demars and Schunk, 2007). Therefore measuring this structure is important when considering the overall global thermospheric energy balance and also the extent of neutral control of ionospheric flows and energetics through ion-neutral coupling. The colocation of the instrument with ESR has been used to compare ion temperatures to neutral temperatures and demonstrate the consistency of the combined measurements. Combining the SCANDI measurements with relevant local ionospheric measurements is vital to understand the drivers behind the observed neutral structure.

The SCANDI observations shown in the bottom three plots of Fig. 3 can clearly be related to the EISCAT Svalbard Radar measurements shown in the top two plots. Three periods of importance are described in the data section. The first two are periods of particle precipitation and the third of ion temperature increases. The first of these is an F-region enhancement by a factor of 3 between 21:15 UT and 21:30 UT. This accounts for the rapid increase in the $630 \mathrm{~nm}$ emission because dissociative recombination is the dominant production process for $630 \mathrm{~nm}$ in the nighttime hours, and so the intensity is proportional to the electron density (Hays et al., 1978). The height profile of the electron density also shows an increase over the altitudes $100-200 \mathrm{~km}$. As a consequence the peak emission height will be lowered from the usual $250 \mathrm{~km}$. This accounts for the drop in the neutral temperature since the FPI is sampling the temperature characteristic of a lower altitude. Once the precipitation is ended (around 22:10 UT) and the $630 \mathrm{~nm}$ intensities have returned to their previous level, the neutral temperatures are seen to rise back over a half-hour period to those more typical of $250 \mathrm{~km}$.

Holmes et al. (2005) identify similar effects when observing the $557.7 \mathrm{~nm}$ emission in the lower thermosphere with their Scanning Doppler Imager (SDI). The large temperature gradient with altitude in the lower thermosphere results in dramatic observed neutral temperature changes during auroral emission intensity enhancements caused by hard electron precipitation. The effect has also been observed with standard FPI observations of the $557.7 \mathrm{~nm}$ emission and combined with ion temperature measurements from the mainland EISCAT UHF radar (Griffin et al., 2006). The neutral temperature results presented here show that the effect can also be dramatic in the upper thermosphere. In contrast to the lower thermosphere, the upper thermosphere is expected to exhibit a much smaller temperature gradient with altitude and should result in less pronounced temperature changes in the presence of $630 \mathrm{~nm}$ emission intensity enhancements caused by soft electron precipitation. The dramatic changes shown here may be due to the low background level of $630 \mathrm{~nm}$ emission in the very low solar activity conditions in early 2007 which allows the precipitation-enhanced emission to dominate.

The second period from 21:45 to 22:10 UT has hard electron precipitation enhancing the E-region with a little Fregion enhancement. Consequently the $630 \mathrm{~nm}$ intensity which has been dying away after the first period of precipitation is boosted a little. The ESR data show strongly enhanced ion temperatures at all heights, likely to result from strong frictional heating driven by enhanced electric fields. However, the neutral temperature remains low partly due to the larger thermal capacity of the neutral atmosphere but also as the FPI is still sampling a lower height region.

The third period shows the consequence of Joule heating due to the difference between the ion and neutral velocities. Heating is indicated by a gradual increase in neutral temperature by around $200 \mathrm{~K}$ in all directions and the surge in the neutral winds. The ESR shows sporadic doubling of the ion temperatures throughout this period. This contrasts with the later post-midnight period in which neutral temperatures gradually fall throughout. Figure 4 shows how the ion temperature at $245 \mathrm{~km}$ during this period drops below the neutral temperature. This is not realistic and so it is proposed that these lower values may be underestimates as a result of changes in composition (McCrea et al., 1995; Aruliah et al., 2005). The standard radar analysis assumes $100 \%$ atomic oxygen at $245 \mathrm{~km}$. Joule heating produces expansion of the atmosphere which elevates molecular constituents, thus altering the ratio of atoms to molecules. As a consequence the calculated ion temperature values may be underestimates of the likely true values. Support for this explanation is provided by the neutral vertical velocities observed by the FPI during this time shown in Fig. 5. The prolonged period of upwelling revealed pre-midnight may then result in a sufficiently altered ratio of atoms to molecules to produce the apparent underestimate of ion temperature in the post-midnight period.

\section{Conclusions}

First results from the new SCANDI instrument have been combined with data from a standard FPI for the night of 15 March 2007 to demonstrate consistent upper thermospheric neutral winds and temperatures. Discrete spatial structure is also evident in the neutral winds results when comparing adjacent SCANDI zones separated by around $220 \mathrm{~km}$. By combining both optical instruments with the ESR it has been possible to investigate the coupled behaviour of the ionospherethermosphere system. The combined optical and radar results have shown how the nature of precipitation can control the altitude of the $630 \mathrm{~nm}$ emission and the consequent effects on neutral temperature measurements. The ability to investigate discrete small scale structure with SCANDI will be important when examining the influence of the ion velocities on the extended neutral wind field. Future experiments will combine the ion velocities measured with the Cutlass radars with the SCANDI neutral winds to study the dynamics of ion-neutral coupling over an extended spatial field. The ESR radar will continue to produce high time resolution local measurements that may be used to extend the scales of 
ion-neutral coupling investigated, including scanning experiments within the SCANDI FOV.

Acknowledgements. The authors would like to acknowledge the UK Particle Physics and Astronomy Research Council who have supported the SCANDI and FPI instruments and also the EISCAT Scientific Association who operate the ESR radar. EISCAT is supported by Finland (SA), France (CNRS), Germany (MPG), Japan (NIPR), Norway (NAFN), Sweden (NFS), and the United Kingdom (STFC).

Topical Editor M. Pinnock thanks M. Ishii for his help in evaluating this paper.

\section{References}

Aruliah, A. L. and Griffin, E. M.: Meso-scale structure in the highlatitude thermosphere, Ann. Geophys., 19, 37-46, 2001, http://www.ann-geophys.net/19/37/2001/.

Aruliah, A. L., Griffin, E. M., McWhirter, I., Aylward, A. D., Ford, E. A. K., Charalambous, A., Kosch, M. J., Davis, C. J., and Howells, V. S. C.: First tristatic studies of meso-scale ion-neutral dynamics and energetics in the high-latitude upper atmosphere using collocated FPIs and EISCAT radar, Geophys. Res. Lett., 31, L03802, doi:10.1029/2003GL018469, 2004.

Aruliah, A. L., Griffin, E. M., Aylward, A. D., Ford, E. A. K., Kosch, M. J., Davis, C. J., Howells, V. S. C., Pryce, E., Middleton, H., and Jussila, J.: First direct evidence of meso-scale variability on ion-neutral dynamics using co-located tristatic FPIs and EISCAT radar in Northern Scandinavia, EISCAT workshop special issue, Ann. Geophys., 23, 147-162, 2005, http://www.ann-geophys.net/23/147/2005/.

Biondi, M. A., Zipf, M. E., Sipler, D. W., and Baumgardner, J. L.: All-Sky Doppler Interferometer for thermospheric dynamics studies, Appl. Optics, 34, 1647-1654, 1995.

Burnside R. G., Herrero, F. A., Meriwether Jr., J. W., and Walker, J. C. G.: Optical Observations of Thermospheric Dynamics at Arecibo, J. Geophys. Res., 86, 5532-5540, 1981.

Codrescu, M. V., Fuller-Rowell, T. J., Foster, J. C., Holt, J. M., and Cariglia, S. J.: Electric field variability associated with Millstone Hill electric field model, J. Geophys. Res., 105, 52655273, 2000.

Conde, M. and Smith, R. W.: Phase compensation of a separation scanned, all-sky imaging Fabry-Perot spectrometer for auroral studies, Appl. Optics, 36, 5441-5450, 1997.
Demars, H. G. and Schunk, R. W.: Thermospheric response to ion heating in the dayside cusp, J. Atmos. Sol.-Terr. Phys., 69, doi:10.1016/j.jastp.2006.11.002, 2007.

Greet, P. A., Conde, M. G., Dyson, P. L., Innis, J. L., Breed, A. M., and Murphy, D. J.: Thermospheric wind field over Mawson and Davis, Antarctica: simultaneous observations by two Fabry-Perot spectrometers of $630 \mathrm{~nm}$ emission, J. Atmos. Sol.Terr. Phys., 61, 1025-1045, 1999.

Griffin, E. M., Kosch, M. J., Aruliah, A. L., Kavanagh, A., McWhirter, I., Senior, A., Ford, E. A. K., Davis, C., Abe, T., Kurihara, J., Kauristie, K., and Ogawa, Y.: Combined groundbased optical support for the aurora (Delta) sounding rocket campaign, Earth, Planets Space, 58, 1113-1121, 2006, 2006.

Hays, P. B., Rusch, D. W., Roble, R. G., and Walker, J. C. G.: The O I (6300 Å) airglow, Rev. Geophys. Space Phys., 16, 225-232, 1978.

Holmes, J. M., Conde, M., Deehr, C., and Lummerzheim, D.: Morphology of evening sector aurorae in $557.7 \mathrm{~nm}$ Doppler temperatures, Geophys. Res. Lett., 32, L02103, doi:10.1029/2004GL021553, 2005.

Ishii, M., Conde, M., Smith, R. W., Krynicki, M., Sagawa, E., and Watari, S.: Vertical wind observations with two Fabry-Perot interferometers at Poker Flat, Alaska, J. Geophys. Res., 106, 10 537-10 551, 2001.

Killeen, T. L., Won, Y.-I., Niciejewski, R. J., and Burns, A. G.: Upper Thermosphere Winds and Temperatures in the Geomagnetic Polar Cap: Solar Cycle, Geomagnetic Activity and IMF Dependencies, J. Geophys. Res., 100, 21 327-21 342, 1995.

McCrea, I. W., Jones, G. O. L., and Lester, M.: The BEAN experiment - An EISCAT study of ion temperature anisotropies, Ann. Geophys., 13, 177-188, 1995, http://www.ann-geophys.net/13/177/1995/.

Nakajima, H., Okano, S., Fukunishi, H., and Ono, T.: Observations of thermospheric wind velocities and temperatures by the use of a Fabry-Perot Doppler imaging system at Syowa Station, Antarctica, Appl. Optics, 34, 8382-8395, 1995.

Rees, D. and Greenaway, A. H.: Doppler imaging system, an optical device for measuring vector winds, 1, General principles, Appl. Optics, 22, 1078-1083, 1983.

Rees, D., Greenaway, A. H., Gordon, R., McWhirter, I., Charleton, P. J., and Steen, A.: The Doppler Imaging System: Initial Observations of the Auroral Thermosphere, Planet. Space Sci., 32, 273-285, 1984. 